\title{
Autoradiographic Determination of Regional Cerebral Blood Flow in the Immature Rat
}

\author{
DAVID T. LYONS, FRANCESCA VASTA, AND ROBERT C. VANNUCCI \\ Department of Pediatrics, Division of Newborn Medicine, Baystate Medical Center, Springfield, Massachusetts \\ [D.T.L.] and Department of Pediatrics, Division of Pediatric Neurology, M. S. Hershey Medical Center, \\ Pennsylvania State University, Hershey, Pennsylvania [F.V., R.C.V.]
}

\begin{abstract}
Seven-day-old rats ( $15 \mathrm{~g}$ body weight) were injected subcutaneously with iodo- $-\left[{ }^{14} \mathrm{C}\right]$ antipyrine $(5 \mu \mathrm{Ci})$. After a variable period, each pup was decapitated and arterial blood collected for scintillation counting. Brains were immediately removed and either prepared for isotopic counting or frozen for autoradiography. The brain:blood partition coefficient was determined $[0.944 \pm 0.006 \mathrm{ml} / \mathrm{g}$ (mean \pm SEM)]. Both cerebral blood flow (CBF) and regional CBF (RCBF) were calculated according to a formula derived from the Fick equation. CBF equaled $66 \pm 4$ $\mathrm{ml} / 100 \mathrm{~g} / \mathrm{min}$ (mean $\pm \mathrm{SEM}$ ), a value midway between reported 1-day-old rat $\mathrm{CBF}$ and adult rat $\mathrm{CBF}$. Autoradiographs were of sufficient quality to permit microdensitimetric readings of a minimum of 11 structures. RCBF ranged from $20 \mathrm{ml} / 100 \mathrm{~g} / \mathrm{min}$ in subcortical white matte to $71 \mathrm{ml} / 100 \mathrm{~g} / \mathrm{min}$ in the brain stem. Immature rat RCBF, as a proportion of adult rat $\mathrm{RCBF}$, was greatest in brain stem. Previously thought not feasible, this technique provides a reliable and relatively simple means of measuring both CBF and RCBF in the very small laboratory anim-l. (Pediatr Res 21: 471-476, 1987)
\end{abstract}

\section{Abbreviations}

CBF, cerebral blood flow

RCBF, regional cerebral blood flow

$\lambda$, brain:blood partition coefficient

IAP, iodo- $-\left[{ }^{14} \mathrm{C}\right]$ antipyrine

$\left[{ }^{131} I\right] \mathrm{CF}_{3} \mathrm{I},{ }^{131}$ I-labeled trifluoroiodomethane

Interest in the neurologic problems of the human newborn (intraventricular hemorrhage, hypoxic-ischemic encephalopathy, cerebral infarction, kernicterus) has prompted numerous studies of $\mathrm{CBF}$ and $\mathrm{RCBF}(1-5)$. Although a variety of methods has been utilized to measure RCBF, all require a fairly large animal for study. The microsphere technique, originally described by Rudolph and Heymann (6), has been applied extensively to the study of lamb and piglet cerebral circulation $(3,7)$. This technique is limited to larger animals by the requirement for catheterization of major vessels. Autoradiographic techniques derived from work of Kety $(8,9)$ have also been used to measure RCBF in newborn animals, primarily immature dogs $(10,11)$. The need for vessel catheterization, as well as intraabdominal surgery for

Received January 23, 1986; accepted December 9, 1986.

Address for correspondence David T. Lyons, M.D., Baystate Medical Center, Division of Newborn Medicine, 759 Chestnut Street, Springfield, MA 01199.

Supported by Grant 15738 from the National Institutes of Child Health and Human Development. D.T.L. is the recipient of an institutional National Research

Service Award from the National Institute of Neurological and Communicative Diseases and Stroke. $\lambda$ determination, makes successful application of this technique to small mammals unlikely.

We previously developed a model of hypoxic-ischemic encephalopathy in the immature rat. Following right common carotid artery ligation and exposure to an $8 \%$ oxygen environment, 1-wk-old rats develop reproducible brain damage (12). To determine the role of ischemia in production of this damage, we adapted one of the autoradiographic techniques noted above for $\mathrm{RCBF}$ determination in 7-day old rats. In the present report we describe application of this modified technique to the study of normal newborn rats. This successful application made possible measurement of RCBF in our model of hypoxic-ischemic encephalopathy (13).

\section{MATERIALS AND METHODS}

Dated pregnant Sprague-Dawley rats were purchased from a commercial breeder and allowed to deliver spontaneously. Newborn rats were kept with their dams up to a few minutes prior to experimentation, which took place at 7 days of postnatal age. Rat pups used in any given experiment were of similar weight, and where possible, from the same litter.

Each rat was injected subcutaneously with $5 \mu \mathrm{Ci}$ of IAP (53 $\mathrm{mCi} / \mathrm{mmol}$; New England Nuclear, Boston, MA). The injection was made into the back of the rat, roughly in the midline. Any observed bleeding or leakage from the injection site resulted in exclusion of the animal from the study (on average one to two animals per litter). After a variable time, the animal was decapitated and blood was collected from the trunk into a heparinized glass capillary tube. Ten $\mu l$ of blood pipetted from the capillary tube was added to a scintillation vial containing $1 \mathrm{ml}$ of Soluene350 (United Technologies Packard, Downers Grove, IL). After mixing overnight in a mechanical shaker, the solution was combined with $9 \mathrm{ml}$ of Dimilume-30 (United Technologies Packard). Samples then were counted on a Beckman LS-350 liquid scintillation counter.

The brains of some rat pups were removed from their skulls, and one or both cerebral hemispheres, sectioned at the ponsmidbrain junction, were placed in scintillation vials with $1 \mathrm{ml}$ of soluene-350 per $100 \mathrm{~g}$ brain weight. After mixing overnight, a 1$\mathrm{ml}$ aliquot was added to $9 \mathrm{ml}$ of Dimilume-30 and isotopically counted. Other brains were removed from their skulls and immediately frozen whole in liquid freon $\left(-70^{\circ} \mathrm{C}\right)$. Coronal sections were cut at $20 \mu \mathrm{m}$ thicknesses in a cryostat kept at $-12^{\circ} \mathrm{C}$. Sections were mounted on glass slides, dried, and subjected to quantitative carbon-14 autoradiography along with carbon-14 methylmethacrylate standards. These had been calibrated against standards for $20 \mu \mathrm{m}$ dried brain tissue sections by the manufacturer (Amersham, Arlington Heights, IL). Comparison of optical densities of portions of the autoradiograms corresponding to specific brain regions with those of the carbon-14 standards yielded concentrations $(\mathrm{m} \mu \mathrm{Ci} / \mathrm{g})$ of IAP. 
Preliminary studies were performed to determine a postinjection interval during which blood and brain IAP concentrations were stable. Six 7-day-old rats then received $5 \mu \mathrm{Ci}$ of IAP subcutaneously and were sacrificed during this interval (20 min postinjection). Individual partition coefficients were calculated from brain and blood IAP measurements. The mean partition coefficient was used to calculate $\mathrm{CBF}$ as described below.

The primary goal of our initial experiment was to determine whether alteration of the injection-to-sacrifice interval altered calculated CBF. If calculated CBF did not increase or decrease with progressive changes in the study interval, then the interval could be chosen so as to optimize autoradiograph quality. In this initial CBF experiment, rat pups were sacrificed at predetermined intervals $15 \mathrm{~s}$ to 5 min postinjection. Blood was collected from each rat, while brains were removed only from those animals sacrificed at $1,2,3,4$, or $5 \mathrm{~min}$. These brains were prepared for scintillation counting only. A total of 35 animals from three litters was used. Cerebral hemispheric blood flow was calculated for each interval (1, 2, 3, 4, or $5 \mathrm{~min})$, using averaged values for blood and brain concentrations.

Subsequent experiments $(n=5)$ were performed on single litters to minimize the variability of animal size occurring among litters. Within each litter, individual rats were sacrificed at 15 -s intervals postinjection, up to the 2-min endpoint. Additionally, three to five animals in each litter were sacrificed at $2 \mathrm{~min}$. Brains, taken from this latter group only, were studied using either liquid scintillation counting or quantitative autoradiography.

Both $\mathrm{CBF}$ and $\mathrm{RCBF}$ were calculated according to an equation derived by Kety $(8,9)$ :

$$
C_{B}(T)=\lambda \cdot K \int_{0}^{T} C_{A} \cdot e^{-k(T-t)} d t
$$

where: $C_{B}(T)=$ the concentration of tracer in brain at time $T$ $(\mathrm{dpm} / \mathrm{g}) ; \lambda=$ brain:blood partition coefficient $(\mathrm{ml} / \mathrm{g}) ; \mathrm{K}=$ flow/ $\lambda\left(\mathrm{min}^{-1}\right) ; \mathrm{C}_{\mathrm{A}}=$ the concentration of tracer in blood $(\mathrm{dpm} / \mathrm{ml})$; $\mathrm{T}=$ time at end of experiment; and $\mathrm{t}=$ some time between 0 and $\mathrm{T}$.

To solve the equation, a series of substitutions were made for $\mathrm{K}$. The value of the integral was estimated using the trapezoid rule. Whichever $K$ provided the calculated value of $C_{B}(T)$ closest to the observed value of $C_{B}(T)$ was the solution. This $K$, multiplied by $\lambda$, equaled flow.

Note: In Kety's original equation for inert gas exchange between blood and tissue, $\mathrm{K}$ was defined as follows: $\mathrm{K}=\mathrm{m}$. flow/ $\lambda$ where $m$ was a constant between 0 and 1 that represented the diffusibility of a substance. In the absence of diffusion limitations, $m$ was equal to 1 and therefore inconsequential in the relationship between $\mathrm{K}$ and blood flow to a given tissue. An inert gas, $\left.{ }^{131} 1\right] \mathrm{CF}_{3} \mathrm{I}$, was initially used for $\mathrm{CBF}$ determinations, in part because it had unrestricted diffusibility across the blood-brain barrier. Because CBF measurements performed with IAP are essentially equal to those made with $\left[{ }^{131}{ }^{1}\right] \mathrm{CF}_{3} \mathrm{I}$, it has been concluded that no diffusion limitation for IAP exists in the brain (14).

\section{RESULTS}

Preliminary studies demonstrated that blood IAP concentrations plateaued at $5 \mathrm{~min}$ postinjection. Brain IAP concentrations did not plateau until approximately $10 \mathrm{~min}$ postinjection. Once peak concentrations were achieved, both blood and brain values remained unchanged up to $30 \mathrm{~min}$. Brain and blood IAP concentrations measured 20 min postinjection in six animals were used to calculate individual brain:blood partition coefficients. The mean brain:blood partition coefficient was $0.944 \mathrm{ml} / \mathrm{g}$ with a SE of 0.006.

Individual measurements for our initial CBF experiment are shown in Figure 1. There was a rapid increase in blood concentration of IAP between 15 and $30 \mathrm{~s}$ postinjection. The rate of rise in blood concentration tapered off by $2.5 \mathrm{~min}$. Brain concentration showed its most rapid rate of rise between 1 and 2 min and began to level off by $4 \mathrm{~min}$.

CBF was calculated for each of the five time intervals in our initial experiment using averaged blood and brain concentrations. No systematic difference in flow calculations was found. Such a difference would not be expected given the low flow values measured (15). The 2-min interval was chosen as the study period for subsequent experiments in order to maximize contrast on the autoradiographs. The brain has no diffusion limitation to IAP; thus IAP entry is flow dependent. As study period length is increased, each area receives a greater cumulative flow. As more and more brain regions approach equilibrium for IAP concentration, diminished range of density on the autoradiograph should result. Use of the 2-min time interval allowed us to avoid this source of error.

Relevant "2-min" data from the initial CBF experiment described above were combined with data from all subsequent studies. One blood concentration curve was determined for each of the eight litters studied. Hemispheric brain concentration was measured in 14 rat pups. Comparison of each brain concentration to its litter-matched blood curve provided $14 \mathrm{CBF}$ measurements. Individual CBF measurements are recorded in Table 1. Mean CBF equaled $66 \mathrm{ml} / 100 \mathrm{~g} / \mathrm{min}$ with a SEM equal to 4 .

For calculation of individual RCBF values, regional brain concentrations from 14 rat brains were matched with their litterappropriate blood concentration curves (total five). Mean RCBF data for the 11 regions studied are reported in Table 2 . The greatest measurable flow was to the brainstem while flows to cortex and the basal ganglia were intermediate. As expected, white matter flow was the lowest of all analyzed structures.

Examples of rat brain autoradiographs are shown in Figure 2. Only large readily identifiable areas were used for RCBF calculations. Many small structures (inferior colliculus, oculomotor nucleus, superior olivary nucleus) could be identified but their size prohibited accurate microdensitometric readings. The hippocampus showed a particularly dense pattern of isotope accumulation. Although not quantifiable, flow to this structure was clearly greater than flow to any of the structures listed in Table 2.

\section{DISCUSSION}

Seven-day-old rats weigh approximately $15 \mathrm{~g}$. As a result, catheterization of major vessels is not feasible. Therefore a number of modifications in the indicator diffusion technique were required. First, isotope was administered subcutaneously as a bolus rather than as an intravenous infusion. IAP, administered subcutaneously, takes longer to appear in arterial blood than isotope given intravenously. The subcutaneous route is also associated with a more gradual increase in blood concentration. Fortunately the exact form of the arterial curve is not critical. The curve does increase monotonically; therefore, the requirements of the method are met.

Second, blood was not collected from a catheterized artery, but rather from severed neck vessels. As a result, it is not possible to rule out some contamination of carotid and vertebral artery blood with venous blood. In order to determine the degree of contamination, oxygen saturation of blood collected from the severed trunks of six 7-day-old rats was measured. Oxygen saturation averaged $85 \%$, indicating the blood was primarily of arterial origin. We then attempted to estimate the effect of potential contamination on calculated blood flow. CBF calculations were made using reduced values for a hypothetical blood concentration curve. A range of brain concentrations were employed. If all values in the blood concentration curve were reduced $10 \%$, then CBF values were increased only $7 \%$ (range 6 to $9 \%$ ). Given the near normal oxygen saturations observed, we concluded that any error produced by this blood collection method must be small. 

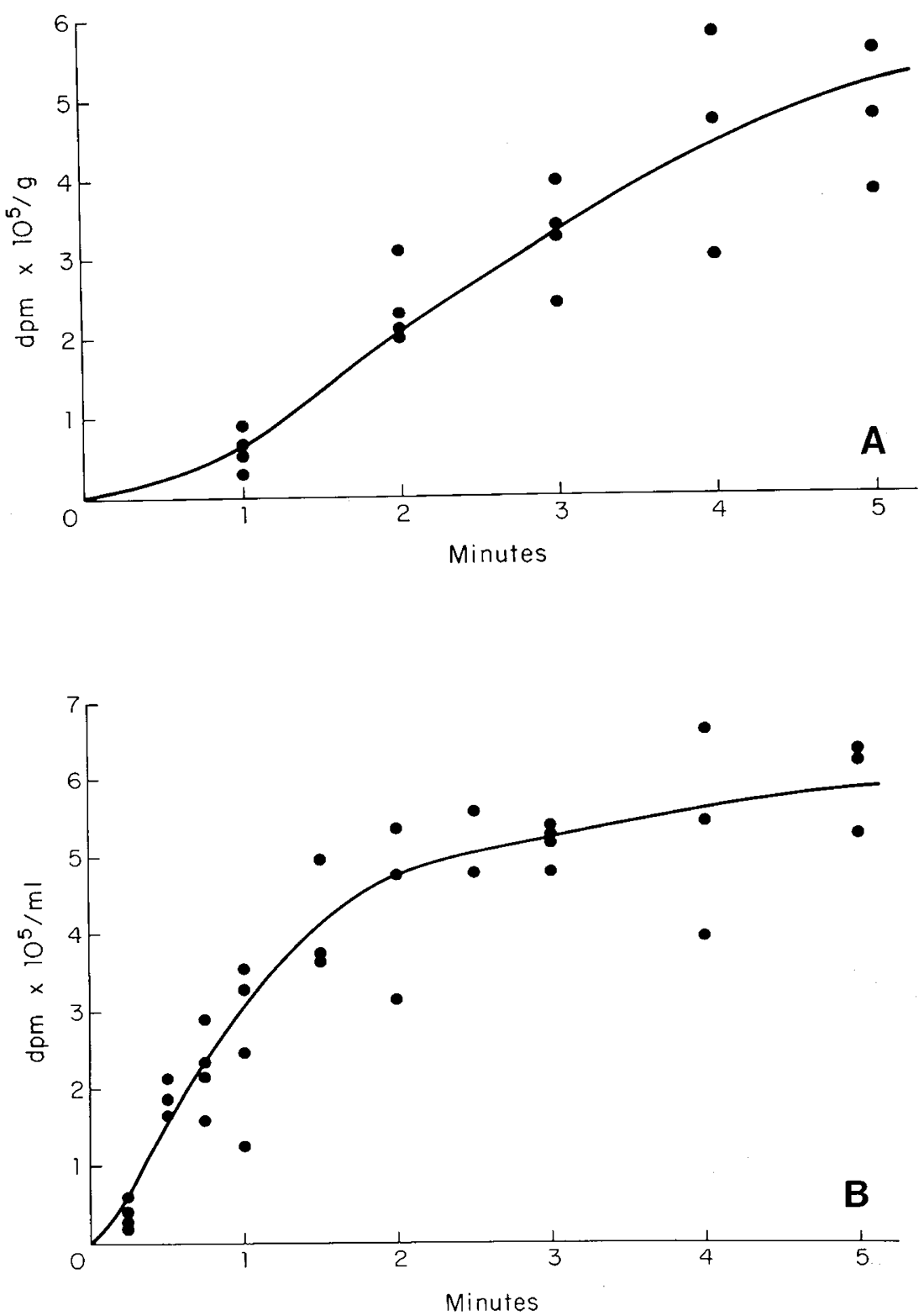

Fig. 1. Brain $(A)$ and blood $(B)$ concentrations of IAP over a 5-min period beginning immediately postisotope injection. Study animals were 7day-old rats.

Equally important, the error should be consistent. It is likely that the same degree of venous contamination occurs with each blood collection. Therefore interanimal comparisons should be valid. All flow calculations, whether hemispheric or regional, should be equally exaggerated. This assumption of equal venous contamination becomes irrelevant when we consider intraanimal comparisons. All regional data in a given animal will be derived from the same blood curve.

Third, blood concentration curves were determined from groups of rats rather than from a single rat over time. Only intermediate-sized littermates were studied in a given experiment. Average weight was approximately $15 \mathrm{~g}$ with a range from 13 to $17 \mathrm{~g}$. Because some animals were larger or smaller than the average, blood concentrations in those animals would have to be lower or higher than under ideal circumstances. To estimate the effect of this random variation, $\mathrm{CBF}$ was calculated for a typical blood concentration curve. Then the blood curve was modified so that alternate blood concentration values were either increased or decreased by the same proportion. This modification produced no change in calculated CBF.

It is worth noting that the adaptations we have employed in order to quantify newborn rat RCBF are not unique to our study. Fuglsang et al. (16), faced with the same inability to cannulate arteries and veins, similarly modified the integral method. In this study an arterial blood concentration curve was reconstructed from blood collected at decapitation of a series of newborn rats (16).

Our derivation of $\lambda$ requires some additional comment. Typically circulation to the liver and kidneys is interrupted in order to prevent metabolism or excretion of the tracer. We did not ligate the portal vein, the hepatic artery, the mesenteric arteries, and the renal arteries because these procedures are technically very difficult and would have certainly disrupted rat pup homeostasis, possibly invalidating the partition coefficient measurement. Instead, we measured the partition coefficient while brain and blood concentrations were stable (and presumably in equilibrium). Excretion of the isotope is irrelevant as long as blood levels have been stable for a prolonged period prior to partition coefficient determination. Metabolism of the isotope is potentially a problem (conversion to radioactive metabolites with different chemical properties), but newborn rats have little oxidizing enzyme activity for antipyrine (17). Furthermore, the time 
in which metabolism could have occurred was very short.

Our determination of $\lambda$ in the 1-wk-old rat, $0.944 \mathrm{ml} / \mathrm{g}$, corresponds to previously reported values. Adult rat $\lambda$ equals $0.78 \mathrm{ml} / \mathrm{g} \mathrm{(14)}$ while 3 - to 12 -h-old rat $\lambda$ is reported to be 1.00

Table 1. Hemispheric CBF determinations in individual 7-dayold rats based on scintillation counting of brain IAP concentration 2 min postinjection

\begin{tabular}{cccc}
\hline & \multicolumn{3}{c}{$\begin{array}{c}\text { CBF } \\
(\mathrm{ml} / 100 \mathrm{~g} / \mathrm{min})\end{array}$} \\
\cline { 2 - 4 } Animal & $\begin{array}{c}\text { Left } \\
\text { hemisphere }\end{array}$ & $\begin{array}{c}\text { Right } \\
\text { hemisphere }\end{array}$ & Average \\
\hline 1 & 66 & & 66 \\
2 & 67 & & 67 \\
3 & 85 & & 85 \\
4 & 48 & 63 & 48 \\
5 & 68 & 73 & 66 \\
6 & 66 & 38 & 70 \\
7 & 37 & 62 & 38 \\
8 & 60 & 86 & 61 \\
9 & 88 & 82 & 87 \\
10 & 64 & 76 & 73 \\
11 & 79 & 66 & 78 \\
12 & 66 & 55 & 66 \\
13 & 55 & 72 & 55 \\
14 & 62 & & 67 \\
Mean & & & $66 \pm 4$ (SEM) \\
\hline
\end{tabular}

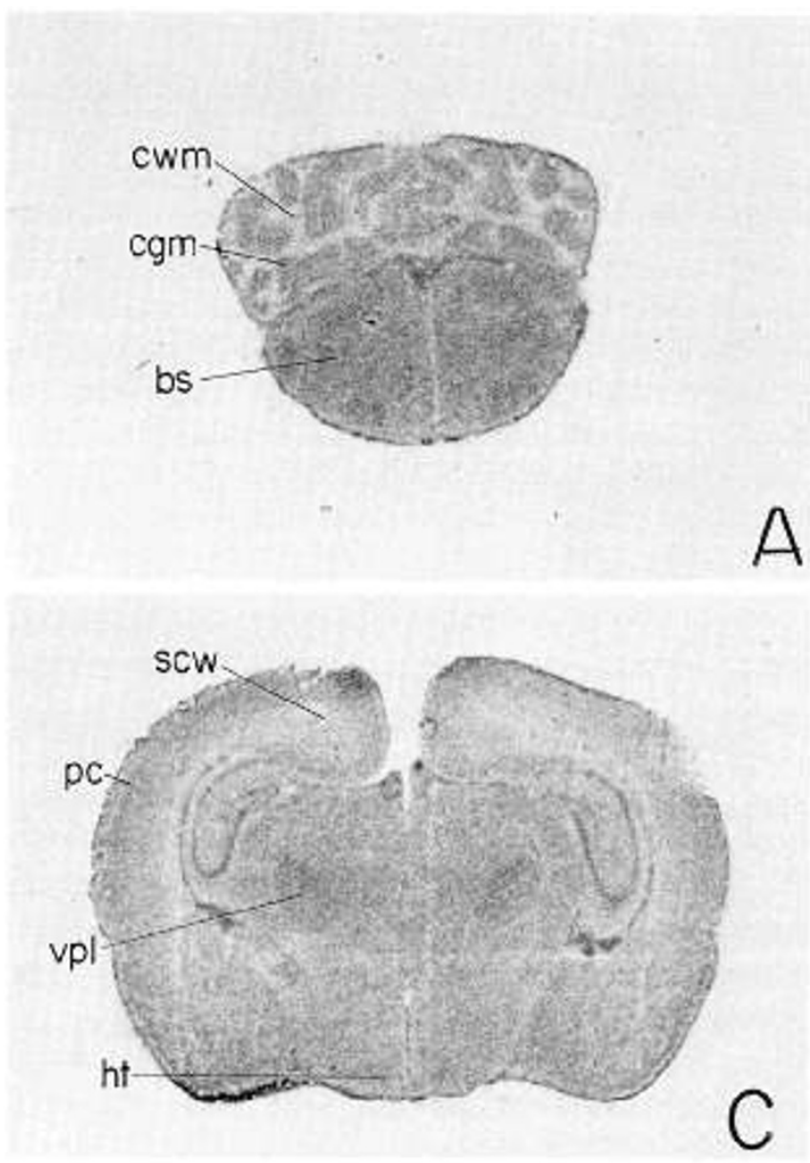

Table 2. Autoradiographic measurements of $R C B F$ in 7-day-old and adult rats

\begin{tabular}{|c|c|c|c|}
\hline \multicolumn{2}{|c|}{ Present study $(n=14)$} & \multicolumn{2}{|c|}{ Sakurada $(n=6)$} \\
\hline Region & $\mathrm{RCBF}^{*}$ & Region & $\mathrm{RCBF}^{*}$ \\
\hline Brainstem & & Brainstem & \\
\hline Medulla-pons $\dagger$ & $71 \pm 8$ & Pontine gray & $102 \pm 7$ \\
\hline Cortex & & Cortex & \\
\hline Frontal & $66 \pm 5$ & Frontal & $139 \pm 9$ \\
\hline Parietal & $53 \pm 5$ & Parietal & $169 \pm 13$ \\
\hline Occipital & $46 \pm 4$ & Occipital & $150 \pm 12$ \\
\hline Deep gray & & Deep gray & \\
\hline $\begin{array}{l}\text { Ventral posterolateral } \\
\text { nucleus }\end{array}$ & $63 \pm 7$ & Thalamus:ventral & $139 \pm 6$ \\
\hline Thalamus & $44 \pm 3$ & Thalamus:lateral & $160 \pm 9$ \\
\hline Hypothalamus & $52 \pm 5$ & Hypothalamus & $86 \pm 4$ \\
\hline Caudate & $42 \pm 4$ & Caudate-putamen & $137 \pm 4$ \\
\hline $\begin{array}{l}\text { Putamen-globus palli- } \\
\text { dus }\end{array}$ & $43 \pm 5$ & Globus pallidus & $75 \pm 5$ \\
\hline Cerebellum & & Cerebellum & \\
\hline Cerebellar hemisphere $\dagger$ & $39 \pm 5$ & Cortex & $100 \pm 8$ \\
\hline White matter & & White matter & \\
\hline Subcortical & $20 \pm 2$ & $\begin{array}{l}\text { Corpus callosum } \\
\text { Internal capsule }\end{array}$ & $\begin{array}{l}40 \pm 4 \\
49 \pm 2 \\
\end{array}$ \\
\hline
\end{tabular}

* Expressed in $\mathrm{ml} / 100 \mathrm{~g} / \mathrm{min}$ (mean $\pm \mathrm{SEM}$ ).

$\dagger$ This area studied in 11 animals only.
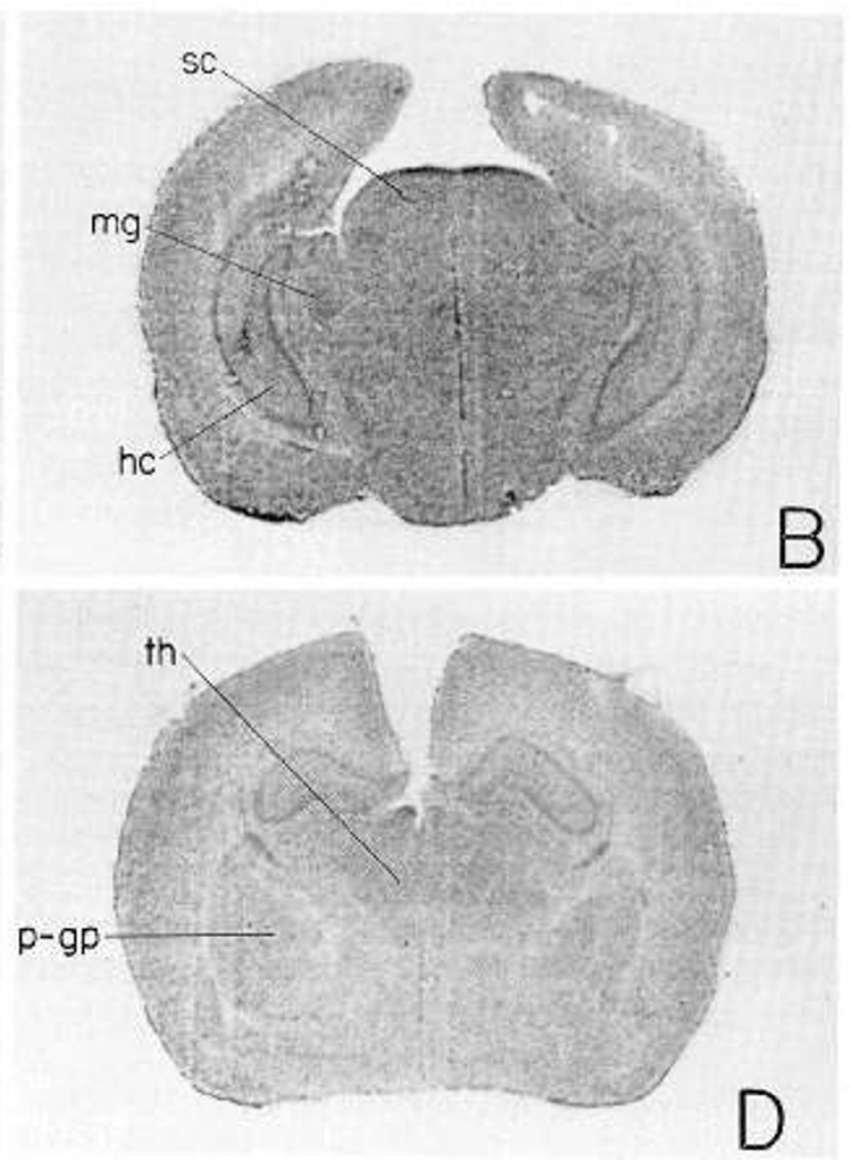

Fig. 2. Autoradiograms of coronal brain sections illustrating RCBF in a 7-day-old rat. Darker regions correspond to areas of greater flow. Sections shown include $A$, brainstem; $B$, midbrain; $C$, thalamus at the level of the VPL nucleus; $D$, a more rostral section of thalamus and basal ganglia. ( $b s$, brainstem; cgm, cerebellar gray matter; $c w m$, cerebellar white matter; $h t$, hypothalamus; $h c$, hippocampus; $m g$, medial geniculate; $p c$, parietal cortex; $p$-gp, putamen-globus pallidus; sc, superior colliculus; $s c w$, subcortical white matter; $t h$, thalamus; $v p l$, ventral posterolateral nucleus). 
$\mathrm{ml} / \mathrm{g}$ (16). It appears that $\lambda$ decreases with age in the rat. This is surprising since there is progressive lipid accumulation in the brain with advancing age and IAP is very lipid soluble. This decrease in $\lambda$ with increasing age has not been seen in other animals. Notably, $\lambda$ increases with age in the piglet (18).

Our hemispheric flow measurements bear comparison to earlier measurements of CBF in the rat (Table 3). Fuglsang et al. (16) using a technique similar to ours and employing IAP as the tracer, found CBF to equal $24 \mathrm{ml} / 100 \mathrm{~g} / \mathrm{min}$ in the 3 - to $12-\mathrm{h}$ old rat. Barker (19), measuring the rate of outflow of cerebral venous blood from the confluence sinorum, found CBF to equal $31.2 \mathrm{ml} / 100 \mathrm{~g} / \mathrm{min}$ in the 1-day-old rat. Moore et al. (20) measured rat CBF using a method based on the permeation rate of tritiated water. They found CBF increased from $34 \mathrm{ml} / 100 \mathrm{~g} /$ $\mathrm{min}$ in the 1-day-old rat to $129 \mathrm{ml} / 100 \mathrm{~g} / \mathrm{min}$ in the 14-day-old animal. Eklof et al. (15), using the Kety-Schmidt $\mathrm{Xe}^{133}$ inhalation technique, found adult rat $\mathrm{CBF}$ to equal $100 \mathrm{ml} / 100 \mathrm{~g} / \mathrm{min}$ [see also Hernandez et al. (21)]. Clearly rat CBF increases over the first 2 wk of life and it is likely that this increase is a gradual one, corresponding to brain maturation. Our measurement of CBF at 7 days of age, $66 \mathrm{ml} / 100 \mathrm{~g} / \mathrm{min}$, supports this contention. Similar increases with age are seen in the dog, another animal with a relatively immature brain at birth $(11,22,23)$.

The doubling in CBF found from birth to 7 days of age corresponds to a doubling in metabolic rate over the same time period. Duffy et al. (24) calculated rates of energy expenditure in rat forebrain under conditions of total ischemia. The energy use rate $(\Delta \sim \mathrm{P})$ increased from $1.33 \mathrm{mmol} \sim \mathrm{P} / \mathrm{kg} / \mathrm{min}$ at 1 day to $2.58 \mathrm{mmoles} \sim \mathrm{P} / \mathrm{kg} / \mathrm{min}$ at 7 days of age [where $\Delta \sim \mathrm{P}=2$. $\Delta \mathrm{ATP}+\Delta \mathrm{ADP}+\Delta \mathrm{P}$-creatine $+2 \cdot \Delta$ glucose $+1.45(\Delta$ lactate $-2 \cdot \Delta$ glucose)]. This suggests that CBF and cerebral metabolic rate are coupled in the developing rat.

While numerous investigators have studied RCBF in adult rats (25-28), no regional data have previously been reported for the immature rat. Sakurada et al. (14) studied RCBF in the adult rat using IAP as the tracer. Table 2 includes their results.

In analyzing our data we observed predominance of brainstem flow as expected for the immature brain $(5,10,23,29)$. This fact is highlighted when comparison is made to adult flow values. While most regions have flows that are approximately $40 \%$ of adult values, brainstem flow is already $70 \%$ of the adult flow. This difference in "blood flow maturity" may be even greater than the numbers indicate. Densitometric readings taken for brainstem and cerebellum undoubtedly include some areas of white matter. Adult values used for this comparison presumably were for gray matter only.

Marked labeling of the hippocampus was unexpected. Sakurada et al. (14) reported adult rat hippocampal flow of $100 \mathrm{ml} /$ $100 \mathrm{~g} / \mathrm{min}$. In the same study cortical flows ranged from 139 to $205 \mathrm{ml} / 100 \mathrm{~g} / \mathrm{min}$. It may be that relatively high hippocampal flow is seen only in immature animals. Review of neonatal dog RCBF data supports this notion. Batton et al. (30), Cavazutti and Duffy (10), and Shapiro et al. (31) all report hippocampal blood flow approximately equal to cortical blood flows.

In conclusion, we have demonstrated a technique for meas-

Table 3. Comparison of $C B F$ data in rats

\begin{tabular}{|c|c|c|c|}
\hline Age & Technique & $\begin{array}{c}\mathrm{CBF} \\
(\mathrm{ml} / 100 \mathrm{~g} / \mathrm{min})\end{array}$ & Reference \\
\hline $3-12 \mathrm{~h}$ & IAP & 24 & Fuglsang et al. (16) \\
\hline 1 day & Cerebral venous outflow & 31.2 & Barker (19) \\
\hline 1 day & Tritiated water & 34 & Moore et al. (20) \\
\hline 7 day & IAP & 66 & Present study \\
\hline $2 \mathrm{wk}$ & Tritiated water & 120 & Moore et al. (20) \\
\hline Adult & Kety-Schmidt Xe $\mathrm{e}^{133}$ & 100 & Eklof et al. (15) \\
\hline Adult & Kety-Schmidt $\mathrm{Xe}^{133}$ & 103 & $\begin{array}{l}\text { Hernandez et al. } \\
\quad \text { (21) }\end{array}$ \\
\hline
\end{tabular}

urement of RCBF (and CBF) in very small laboratory animals. The technique requires few major resources, is simple to perform, and provides a reliable determination of blood flow to specific areas of immature rat brain.

Acknowledgments. The authors thank Lorraine O'Brien and Maria Lopez for typing the manuscript and Paula Campbell for her expert technical assistance.

\section{REFERENCES}

1. Batton DG, Hellman J, Nardis EE 1984 Effect of pneumothorax-induced pressure alterations on the cerebral circulation in newborn dogs. Pediatrics $74: 350-353$

2. Burgess GH, Oh W, Bratlid D, Bubakk A, Cashore WJ, Stonestreet BS 1985 The effects of brain blood flow on brain bilirubin deposition in newborn piglets. Pediatr Res 19:691-696

3. Laptook A, Stonestreet BS, Oh W 1982 The effects of different rates of plasmanate infusions upon brain blood flow after asphyxia and hypotension in newborn piglets. J Pediatr 100:791-796

4. Pasternak JF, Groothius DR, Fischer JM, Fischer DP 1982 Regional cerebral blood flow in the newborn beagle pup: the germinal matrix is a low flow structure. Pediatr Res 16:499-503

5. Young RSK, Hernandez MJ, Yagel SK 1982 Selective reduction of blood flow to white matter during hypotension in newborn dogs: a possible mechanism for periventricular leukomalacia. Ann Neurol 12:445-448

6. Rudolph AM, Heymann MA 1967 The circulation of the fetus in utero. Circ Res 21:163-184

7. Jones MD, Traystman RJ, Simmons MA, Molteni RA 1981 Effects of changes in arterial oxygen content on cerebral blood flow in the lamb. Am J Physiol 240:H209-H215

8. Kety SS 1951 Theory and applications of the exchange of inert gas at the lungs and tissues. Pharmacol Rev 3:1-41

9. Kety SS 1960 Measurement of local blood flow by the exchange of an inert, diffusible substance. Meth Med Res 8:228-236

10. Cavazutti M, Duffy TE 1982 Regulation of local cerebral blood flow in normal and hypoxic newborn dogs. Ann Neurol 11:247-257

11. Hernandez MJ, Brennan RW, Vannucci RC, Bowman GS 1978 Cerebral blood flow and oxygen consumption in the newborn dog. Am J Physiol 234:R209-R215

12. Rice JE, Vannucci RC, Brierly JB 1981 The influence of immaturity on hypoxic-ischemic brain damage in the rat. Ann Neurol 9:131-141

13. Lyons DT, Vannucci RC 1985 Regional cerebral blood flow (rCBF) in the immature rat. Pediatr Res 19:351A (abstr)

14. Sakurada O, Kennedy C, Jehle J, Brown JD, Carbin GL, Sokoloff L 1978 Measurement of local cerebral blood flow with iodo [14C] antipyrine. Am J Physiol 234:H59-H66

15. Eklof B, Lassen NA, Nilson L, Norberg K, Siesjo BK, Torlof K 1974 Regional cerebral blood flow in the rat measured by the tissue sampling technique; a critical evaluation using four indicators: $\mathrm{C}^{14}$-antipyrine, $\mathrm{C}^{14}$-ethanol, $\mathrm{H}^{3}$ water, and Xenon ${ }^{133}$. Acta Physiol Scand 91:1-10

16. Fuglsang A, Lomholt $M$, Gjedde A 1986 Blood-brain transfer of glucose and glucose analogs in newborn rats. J Neurochem 46:1417-1428

17. Sunouchi M, Tanaka A, Mizokami K, Inoue K, Fujimore K, Kasuya K, Omori Y 1984 Comparison of hepatic drug metabolizing enzymes induced by 3methylcholanthrene and phenobarbital between pre- and postnatal rats. Toxicol Appl Pharmacol 73:457-463

18. Wootton T, Flecknell PA, Royston JP, John M 1983 The tissue-blood partition coefficient of iodoantipyrine in pig brain and its change with age. Can J Physiol Pharmacol 61:595-598

19. Barker JN 1966 Fetal and neonatal cerebral blood flow. Am J Physiol 210:897902

20. Moore TJ, Lione AP, Regan DM, Tarpley HL, Raines PL 1971 Brain glucose metabolism in the newborn rat. Am J Physiol 221:1746-1753

21. Hernandez MJ, Brennan RW, Bowman GS 1978 Cerebral blood flow autoregulation in the rat. Stroke 9:150-155

22. Brennan RW, Patterson RH, Kessler J 1971 Cerebral blood flow during cardiopulmonary bypass: evidence of microembolic encephalopathy. Neurology 21:655-672

23. Kennedy C, Grave GD, Jehle JW, Sokoloff L 1972 Changes in blood flow in component structures of the dog brain during postnatal maturation. J Neurochem 19:2423-2433

24. Duffy TE, Kohle SJ, Vannucci RC 1975 Carbohydrate and energy metabolism in perinatal rat brain: relation to survival in anoxia. $J$ Neurochem $24: 271$ 276

25. Furlow TW, Martin RM, Harrison LE 1983 Simultaneous measurement of local glucose utilization and blood flow in the rat brain: an autoradiographic method using two tracers labeled with carbon-14. J Cereb Blood Flow Metab 3:62-66

26. Lear JL, Jones SC, Greenberg JH, Fedora TJ, Reivich M 1981 Use of ${ }^{123} \mathrm{I}$ and ${ }^{14} \mathrm{C}$ in a double radionuclide autoradiographic technique for simultaneous measurement of LCBF and LCMRgl. Stroke 12:589-597 
27. Mies G, Niebuhr I, Hossman K-A 1981 Simultaneous measurement of blood flow and glucose metabolism by autoradiographic techniques. Stroke 12:581588

28. Schaefer JA, Gjedde A, Plum F 1976 Regional cerebral blood flow in rat using N-[14C] butanol. Neurology 26:394(abstr)

29. Rosenberg AA, Jones MD, Traystman RJ, Simmons MA, Molteni RA 1982 Response of cerebral blood flow to changes in $\mathrm{pCO}_{2}$ in fetal, newborn, and adult sheep. Am J Physiol 242:H862-H866

30. Batton DG, Hellman J, Hernandez MJ, Maisels MJ 1983 Regional cerebral blood flow, cerebral blood velocity, and pulsatility index in newborn dogs. Pediatr Res 17:908-912

31. Shapiro HM, Greenberg JH, Naughton KVH, Reivich M 1980 Heterogeneity of local cerebral blood flow- $\mathrm{PaCO}_{2}$ sensitivity in neonatal dogs. $\mathrm{J}$ Appl Physiol 49:113-118 